\title{
Erratum to: Cloning and characterization of a novel gene that encodes $(S)$ - $\beta$-bisabolene synthase from ginger, Zingiber officinale
}

\author{
Masaki Fujisawa $\cdot$ Hisashi Harada $\cdot$ \\ Hiromichi Kenmoku • Satoru Mizutani • \\ Norihiko Misawa
}

Published online: 7 April 2010

(C) Springer-Verlag 2010

\section{Erratum to: Planta}

\section{DOI 10.1007/s00425-010-1137-6}

Unfortunately, Fig. 4 was incorrect in the online published article. The correct figure is given below.

The online version of the original article can be found under doi:10.1007/s00425-010-1137-6.

M. Fujisawa $\cdot$ H. Harada $\cdot$ N. Misawa

Central Laboratories for Frontier Technology,

Kirin Holdings Co. Ltd., i-BIRD, 3-570, Suematsu,

Nonoichi, Ishikawa 921-8836, Japan
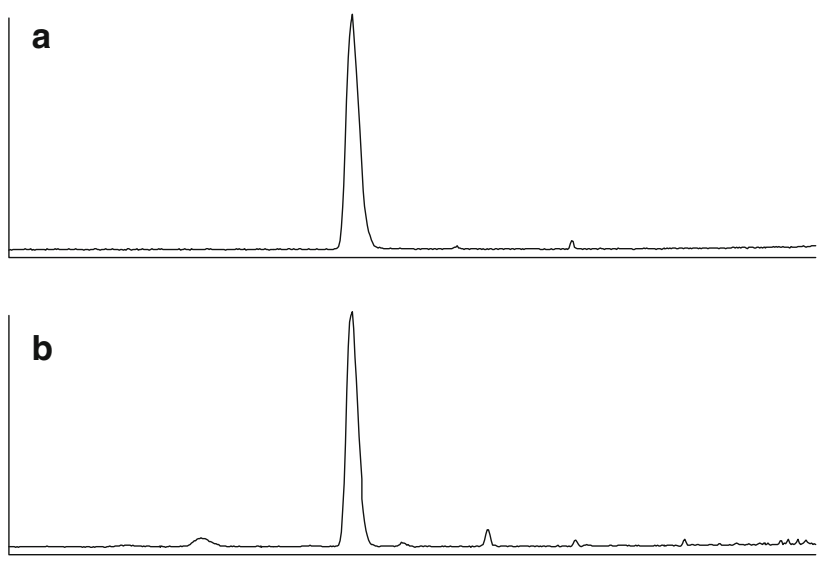

\section{H. Kenmoku}

Institute of Pharmacognosy, Tokushima Bunri University,

Yamashiro, Tokushima 770-8514, Japan

\section{S. Mizutani}

Central Laboratories for Frontier Technology,

Kirin Holdings Co. Ltd., 1-13-5, Fukuura, Kanazawa,

Yokohama 236-0004, Japan

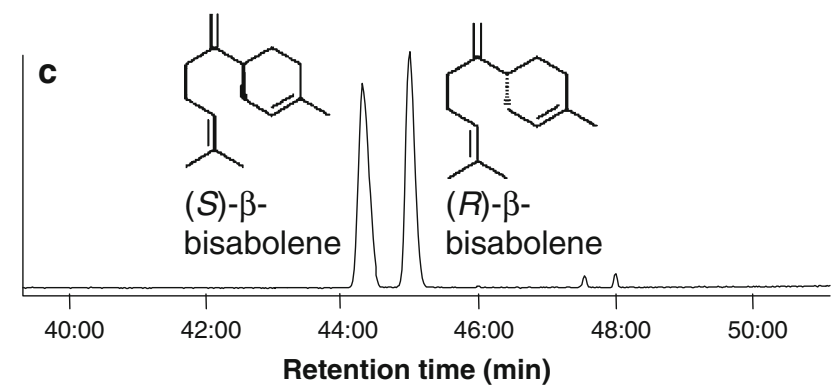

Fig. 4 Identification of the absolute configuration of $\beta$-bisabolene produced by the metabolically engineered E. coli. a Chiral-GC chromatogram of $(S)$ - $\beta$-bisabolene isolated from Bergamot (Citrus bergamia) essential oil. b Chiral-GC chromatogram of dodecane extract from the E. coli strain cotransformed with plasmids pETZo506FL3 and pAC-Mev. c The separation of the enantiomers of $\beta$-bisabolene standard in chiral-GC

Present Address:

N. Misawa $(\square)$

Research Institute for Bioresources and Biotechnology,

Ishikawa Prefectural University, Nonoichi,

Ishikawa 921-8836, Japan

e-mail: n-misawa@ishikawa-pu.ac.jp 